\title{
Measuring the Impacts of Saffron Production Promotion Measures on Farmers' Policy Acceptance Probability: A Randomized Conjoint Field Experiment in Herat Province, Afghanistan
}

\author{
Mohammad Wais Azimy ${ }^{1}$, Ghulam Dastgir Khan ${ }^{1, *}$, Yuichiro Yoshida ${ }^{2}$ and Keisuke Kawata ${ }^{3}$ \\ 1 Graduate School for International Development and Cooperation, Hiroshima University, \\ Higashihiroshima 739-8529, Japan; wais_azimyy@yahoo.com \\ 2 Graduate School for International Development and Cooperation, Hiroshima University and Network for \\ Education and Research on Peace and Sustainability (NERPS), Higashihiroshima 739-8529, Japan; \\ yuichiro@hiroshima-u.ac.jp \\ 3 Institute of Social Science, The University of Tokyo, Tokyo 113-8654, Japan; keisukekawata@iss.u-tokyo.ac.jp \\ * Correspondence: gdkhan.idec@gmail.com
}

Received: 6 April 2020; Accepted: 13 May 2020; Published: 14 May 2020

check for updates

\begin{abstract}
The government of Afghanistan promotes saffron production as a means to achieve economic development while reducing the widely spread opium cultivation in the country by providing necessary support to its farmers via saffron farmer service centers. This study investigates the causal effects of relevant attributes of potential saffron production promotion policies on the participation probabilities of saffron farmers. This study applies a randomized conjoint experiment to primary survey data of 298 farmers in Herat Province, which is perceived by the government as the center of saffron production in the country. The proposed hypothetical saffron production promotion policy consists of six attributes, namely, provision of machinery equipment, weather-based crop insurance, accessibility to long-term loans, location of saffron farmer service centers, provider of services, and annual payment. In the randomized conjoint experiment design, the respondents rank two alternative policies and policies against the status quo. The desirable policy comprises the machinery provision, long-term (up to 5 years) loan accessibility, an easily accessible service center, and policy implementation by international non-governmental organizations (NGOs). The estimated results reveal that saffron farmers are highly supportive of the proposed saffron promotion policy and that their willingness to pay is as high as $17 \%$ of their per capita income.
\end{abstract}

Keywords: saffron production promotion policy; randomized conjoint experiment; willingness to pay; Afghanistan

\section{Introduction}

In Afghanistan, more than 70 percent of the population, including most of the poor, reside in rural areas [1] and their livelihoods depend on agricultural activity [2,3]. As agriculture accounts for a large share of the economy, policy makers and international donors have devoted considerable attention to this sector. The major crops range from grapes and almonds to opium [1], which is traditionally cultivated as a source of income. With the help of international organizations and NGOs, the government of Afghanistan is promoting the replacement of opium cultivation with saffron cultivation, particularly surrounding the Pashtun Zarghun and Ghoriyan districts of Herat Province [4], where opium cultivation has essentially been the only type of agricultural production in which local farmers have engaged. The government of Afghanistan is aiming to increase saffron 
production by replacing opium production [4]; thus, currently, there is an urgent need for an effective saffron production promotion policy. To achieve this goal, the government plans to provide financial and physical support to its farmers via saffron farmer service centers. Thus, this study aims to identify the design of saffron production promotion policy that best meets the needs of saffron farmers by measuring the farmers' participation probabilities conditional on relevant aspects of potential policies by applying the randomized conjoint experiment proposed by Hainmueller et al. [5] to a field experiment conducted in Herat Province, Afghanistan. The government of Afghanistan promotes saffron production as a means to achieve more sustainable economic development while eradicating the widely spread cultivation of opium. Opium cultivation is considered one of the greatest challenges in terms of long-term security, development, and effective governance [6]. Saffron cultivation can deliver the same or even higher incomes for farmers without adverse effects on society [7]. According to a cost-benefit analysis by the Danish Committee for Aid to Afghan Refugees, the daily income for one jerib ( 0.2 hectares) of saffron cultivation is calculated to be $\$ 33$ [8].

The government has distributed free saffron bulbs and provided training programs to farmers in an effort to increase saffron production over the past 15 years. These efforts appear to have had an effect; the Ministry of Agriculture, Irrigation, and Livestock reports that land in Afghanistan under saffron cultivation has increased by $123 \%$ from 2016 to 2018 . Currently, approximately 23,950 farmers, including 20 percent women, are growing saffron in 33 provinces [9], and saffron has become one of Afghanistan's most significant exports. Afghanistan is currently known for producing the finest saffron products, which have earned a global reputation for excellence. For three consecutive years, the International Taste Institute in Brussels has rated Afghanistan's saffron among the world's best [10].

Saffron (Crocus sativus L.) is a member of the Iridaceae family, and the plant's stigmas have been used since ancient times as a dye and cosmetic preparation and for medicinal purposes. Approximately 75,000 crocus flowers or 225,000 stigmas are required to make one pound of this unique spice [11], and saffron is the most expensive spice worldwide for its value by weight, reaching up to 20,000 euro per kilogram [12]. The high price of saffron is partially due to its high labor requirement [12]. On one hectare of land under saffron cultivation, 205 persons are employed per day [13]. Therefore, the cultivation and production of saffron creates numerous job opportunities, especially for women, who perform more than 80 percent of the activities, including collecting flowers, separating the stigmas, drying the saffron, and sorting and grading the final product [14]. There are four different aspects of potentially relevant assistance that could be provided by the government, namely, financial services, mechanization services, insurance services, and farmer service centers. Saffron requires serious investment due to the high cost of saffron bulbs and its high labor requirement, and saffron only begins to provide a return in the second year of cultivation [7]. These issues pose significant challenges for saffron farmers as their access to credit is limited [15]. According to the literature, farmers in developing countries who have access to formal credit have increased agricultural productivity and household incomes [16]. This finding suggests that in our context, access to such credit could also increase saffron production and improve farmers' livelihoods by modernizing the production process.

The mechanization of saffron production can directly affect land and labor productivity and further increase farmers' income and quality of life. For example, drying saffron at air temperature requires up to several days, while drying it with an electric dryer or oven is faster and yields higher quality saffron $[17,18]$. However, to date, mechanization has not been implemented in the production process as many Afghan farmers still use human labor and oxen to plow the land [19]. Additionally, farmers in developing countries are vulnerable to a range of risks, particularly weather risk, which can trap farmers and households in poverty [20]. For instance, reports suggest that saffron farmers in Kashmir, India suffered a tragic 65 percent decline in production [21] due to erratic rain and floods. The government of India assisted its farmers by providing an insurance scheme, which could be applied by the government of Afghanistan.

To meet these needs of saffron farmers in Afghanistan, service centers can play a key role in facilitating and advancing these aims. These centers are designed to support the farming community 
by providing farmers with other much-needed agricultural assistance, such as market information, training classes, management of labor shortages, and quality bulbs, fertilizer, and manure in addition to the provision of machinery equipment and insurance and financial services.

This study uses a randomized conjoint experiment following Hainmueller et al. [5] to gain an understanding of the causal effects of production promotion policy aspects on saffron farmers' policy acceptance probability. In the experiment, we presented a pair of hypothetical saffron production promotion policies consisting of six attributes, namely, the provision of machinery equipment, weather-based crop insurance, accessibility to long-term loans, location of Saffron Production Promotion Service Center (SPPSC), organizer of the policy, and annual payment for providing these services, to the participants. Then, we asked the participants to rank the alternative policies with different levels of these attributes and their willingness to participate. Through the experiment, we obtained primary survey data of 298 farmers. The results show that saffron farmers are highly supportive of the proposed saffron production promotion policy comprising the machinery provision, long-term (up to five years) loan accessibility, easily accessible SPPSC, and implementation of the policy by international NGOs. The lower bound of the willingness to pay (WTP) is estimated as high as $17 \%$ of the farmers' per capita income.

This paper is organized as follows. The following section discusses previous literary work and the background of the agriculture sector of Afghanistan. Section 3 presents our data and empirical strategy, followed by a presentation of the results in Section 4. Finally, Section 5 concludes the paper.

\section{Literature Review}

Agriculture can be the primary source of growth in developing countries and can reduce poverty [22]; however, to achieve these goals, a broad range of policy instruments are needed to render farming more productive and sustainable. Studies have estimated the benefits of formal credit [23-25], mechanization [26,27], insurance [28-32], and agriculture infrastructure for increasing farm productivity and household income in developing countries.

Based on a survey conducted in peanut-growing areas in Niger in West Africa and applying conjoint and ordered Probit analyses, Baidu-Forson et al. [33] found that across all regional and gender subgroups, respondent groundnut farmers attach vital importance to access to credit. Similarly, Moahid and Maharjan [15] conducted a survey of 292 farming households in rural Afghanistan and found that smallholders have little participation in formal credit and remote farmers have limited access to formal credit. They suggest that expansion of formal credit to rural smallholders is crucial for increasing agricultural productivity. Das et al. [34] analyzed the impact of agricultural credit on agriculture production in India using a dynamic panel data analysis with instrumental variables using Arellano-Bond regression and found that the amount of agricultural credit has a positive and statistically significant effect on agriculture production and that the effect can be observed immediately.

These authors further note that agricultural credit and modern technology are essential for realizing higher productivity. Wang et al. [35] investigated whether a crop insurance program is effective in China and used a stochastic simulation model to show that the program increased farmers' welfare. Regarding Afghanistan, Matin [19] argues that the mechanization of agriculture has a direct effect on land and labor productivity, the environment, farm income, and the quality of life of farmers. These previous studies utilized methods, such as conventional conjoint analysis and parametric approaches, to capture the impact of farmer support policies. Rather than using approaches that rely on restrictive assumptions, this study uses a randomized conjoint field experiment to identify the impact of potential saffron production promotion policy attributes on its acceptance by the rural farmers in Afghanistan. Hainmueller et al. [5] restructured the conventional conjoint analysis into a randomized experimental design to estimate the causal effect of each policy component on respondent's choice probabilities without misspecification bias. This new conjoint analysis randomly assigns the attribute levels in each alternative policy while constructing the choice sets, allowing us to identify the causal effects of policy attributes on farmers' policy acceptance decision non-parametrically. 
In recent years, researchers' interest has been growing in estimating the willingness to pay (WTP) of farmers for different agricultural policies for example, promotion of agricultural technology, fertilizer, post-harvest cold storage, and information services [36-39]. We define WTP as the amount that a farmer is willing to pay for a specific good or service. Shee et al. [37] conducted a stated preference-based contingent valuation experiment in Tanzania to estimate farmers' willingness to pay for hybrid maize seed and inorganic fertilizer. They found that farmers' WTP for hybrid maize seed was 61 percent higher than the local market price and for local inorganic fertilizer was 15 percent lower than the market price. Maalouf and Chalak [36] measured farmers' WTP for a post-harvest storage facility in Bekaa valley, Lebanon and found that the majority of the farmers were worrying about the post-harvest losses. They suggested that the farmers should be provided subsidized prices as a great majority of the farmers have the lowest WTP for post-harvest storage facilities. Similarly, Ouédraogo et al. [39] applied a contingent valuation method to measure farmers' WTP for climate information services including seasonal climate forecast, decadal climate information, daily climate information, and agro-advisories in northern Burkina Faso and found that nearly one third of the respondents were ready to pay for these services. Regarding crop insurance, Fahad and Jing [31] conducted a study in Khyber Pakhtunkhwa province, Pakistan using a contingent valuation approach to evaluate demand for weather-based crop insurance. They found that a large parcel of landholders were willing to buy the insurance and the majority of smallholders were reluctant to pay for the crop insurance. This literature has acknowledged the importance of developing relevant policies based on informed decision-making processes by governments in developing countries.

Another contribution we make to the literature is the estimation of the lower bound of respondents' WTP non-parametrically from our randomized conjoint experiment results. We conduct a welfare analysis to compute the potential welfare gain obtained by introducing the new saffron production promotion policy, which includes both pre- and post-harvest services in a single policy package.

Agriculture is the main pillar of Afghanistan's economy, which is the sole source of livelihood for the rural poor [40]; employing 52.6 percent of the rural population [41]. Gross domestic product (GDP) of Afghanistan is USD 20.5 billion including 3 percent from opium poppy cultivation [41]. Wheat is the major cereal crop and a staple food for Afghanistan [3]. However, wheat and other cereal crops such as rice are cultivated for subsistence purposes only. For the rural population, agricultural products including fruits, opium poppy, and recently saffron are the sources of income that could potentially leverage the rural economy of Afghanistan. Among them, opium significantly contributes to the GDP of Afghanistan [41], providing about two hundred thousand of full-time equivalent jobs to local and migrant workers [42]. However, opium cultivation poses other risks to the country, such as health, security, corruption, and financing insurgents [43]. Since the 1980s and during the war time, Afghanistan has become the world's leading producer and exporter of opium [44]. After the fall of the Taliban in 2002, the government of Afghanistan, with the support of the international community, initiated efforts to counter the production of illicit drugs [45]. Several policies were put in place to eradicate opium cultivation including forced eradication and providing cash compensation to the farmers for eradicating the opium crop. However, this policy failed because compensation did not ensure that the farmer would not grow the opium crop again the next year [45]. Forced eradication without providing alternative source of income also proved ineffective and negatively affected the population's income [45]. Therefore, the government of Afghanistan, with the help of the international community, has been promoting licit agricultural production through the introduction of several development programs; for instance, the National Horticulture and Livestock Program (NHLP), implemented by the Ministry of Agriculture, Irrigation, and Livestock (MAIL), aims to improve rural populations' livelihood through promotion of horticulture and livestock [46]; the Comprehensive Agriculture and Rural Development Facility (CARD-F), one of the key development programs of the government of Afghanistan to increase employment, income, and business opportunities in rural areas through the promotion and implementation of agricultural value chains [47]; and the Rural Enterprise Development Program (AREDP), implemented by the Ministry of Rural Rehabilitation and 
Development, aims to increase rural income and employment through strengthening market linkage and value chains for rural enterprises in Afghanistan [48]. Remarkably, in recent years MAIL and other national and international organizations have initiated numerous programs for the promotion of saffron, which is thought to replace opium cultivation in Afghanistan. The government plans to increase the production of the saffron harvest to 100 tons annually by 2028 [49].

Though there is no empirical evidence available showing that saffron can be the best alternative for opium, reports [42] indicate that there is a strong correlation between opium poppy and saffron cultivation. According to the United Nations Office on Drugs and Crime (UNODC) [42], opium cultivation has decreased by 46 percent in Herat Province, while the Ministry of Agriculture, Irrigation, and Livestock of Afghanistan [9] reports that in the same year saffron cultivation has been doubled. This argument leads to discussion on farmers' crop choice, which is, however, out of the scope of this study. Caiserman et. al [50], in a study in Bekaa Valley, Lebanon, discussed farmers' crop choice. They argued that among other factors, market dynamics and agricultural subsidies influence farmers' crop choice. In Afghanistan, the government has made enormous efforts for saffron marketing in China, India, and Gulf countries. Programs such as AREDP provide financial support to saffron enterprises in Herat to participate in commercial exhibitions in other countries for developing market linkages [48]. According to the World Bank [4], AREDP has supported 10 national level exhibitions for saffron enterprises. Moreover, the government has distributed hundreds of tons of saffron corm to farmers in the last two years, which has resulted in an increase in saffron cultivation [49].

\section{Materials and Methods}

\subsection{Description of the Study Area and Content of the Survey Instruments}

This study was conducted in the Ghoriyan, Pashtun Zarghun, and Injil districts located in the western, southeastern, and central parts of Herat Province, respectively, as shown in Figure 1.

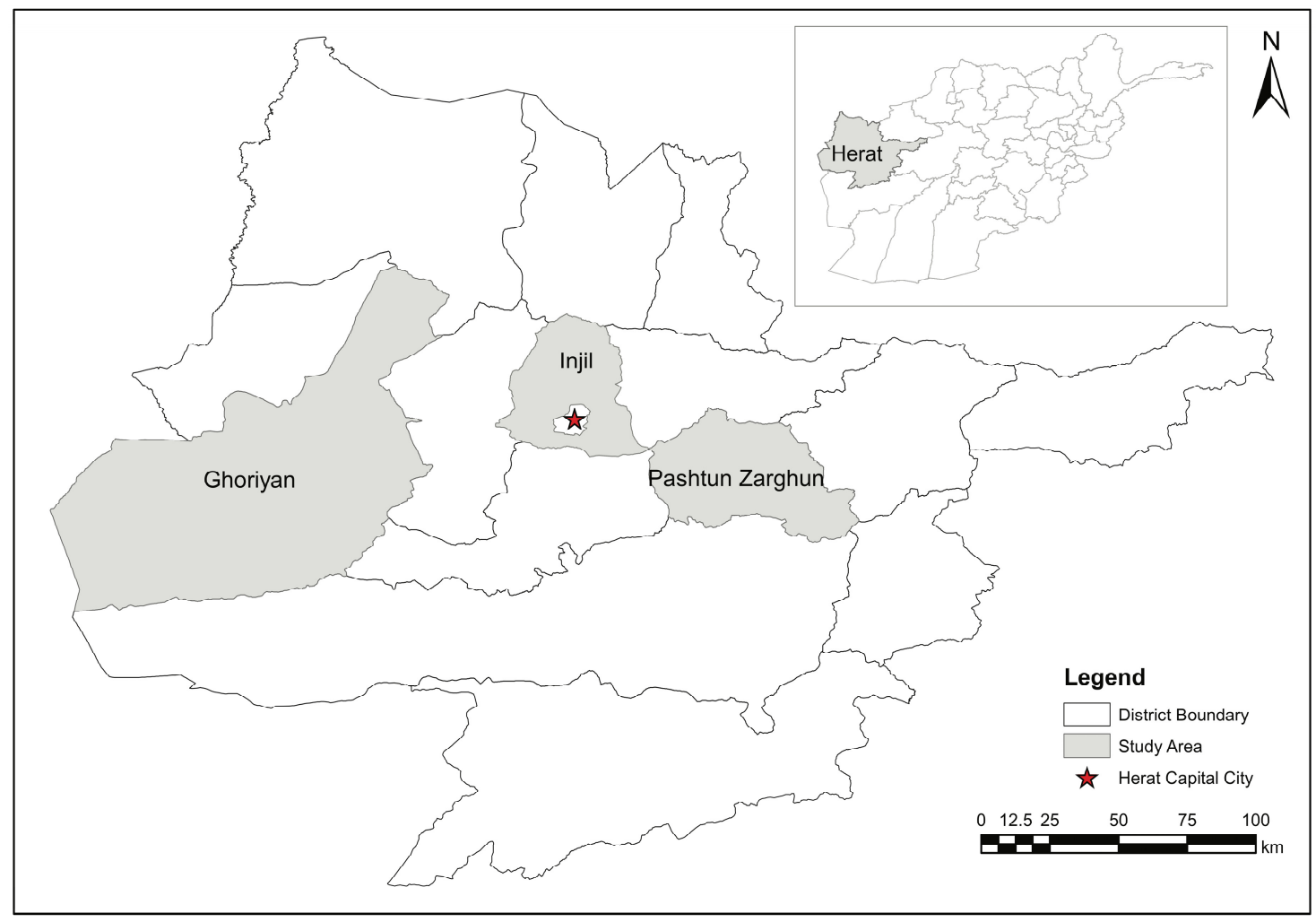

Figure 1. Map depicting the location of the study area (Herat Province) in Afghanistan. Source: Authors. 
Before saffron cultivation began in the province, agriculture was predominantly opium cultivation. Pashtun Zarghun and Ghoriyan were among the first districts to practice saffron cultivation [51]. Currently, Herat Province accounts for 90 percent of Afghan saffron production [52]. The further promotion of saffron production in the region is a top-listed policy agenda for the government of Afghanistan, rendering the area ideal for this study.

The data used in this study were collected via a survey of saffron farmers in three districts of Herat Province, Afghanistan in December 2018 and January 2019. A stratified random sampling design was used to select the respondents. First, three districts in Herat Province were chosen based on saffron production, namely, the districts of Pashtun Zarghun, Ghoriyan, and Injil. Second, five villages were randomly selected from each district. Third, within each village, fifteen to twenty five saffron farmers were randomly chosen from the community list. This procedure yielded a sample of 298 saffron farmers, who were surveyed using face-to-face interviews guided by a questionnaire.

The survey was organized into three parts. The first part asked a set of socioeconomic and demographic questions regarding the farmers' gender, education, farming experience, and farm size. The second part of the survey described a scenario to ensure that the participants understood the meaning of the hypothetical policies and how to rank the different choices based on tiered preferences; the participants were also informed of the assumptions made in the scenarios. The third part included the conjoint experiment questionnaire sheets on which the respondents were asked to state their preferences among the available policy alternatives. The following section describes the design of the experiment in detail.

\subsection{Design of the Choice Experiment}

In each round of our randomized conjoint experiment, the respondents were presented with two different hypothetical policies and an opt-out option, which we call "status quo" in the following text, to allow them to accept neither of the policies. These three alternative choices are labeled choices A, B, and $C$. The respondents were asked to rank these three choices in each round of the experiment, and we repeated this process five times per respondent.

The hypothetical policies presented to the respondents consisted of six attributes describing potentially relevant support for saffron farmers to facilitate and increase saffron production. Thus, these attributes refer to the challenges and constraints faced by farmers, particularly in Afghanistan, as discussed in the previous section. The attributes and their levels are shown in Table 1.

Table 1. List of attributes and their levels.

\begin{tabular}{|c|c|c|c|c|c|}
\hline & Attribute & Level 1 & Level 2 & Level 3 & Level 4 \\
\hline 1 & Saffron Agriculture Crop Insurance & Not Insured & Insured & & \\
\hline 2 & $\begin{array}{l}\text { Saffron Production Loan } \\
\text { Repayment time }\end{array}$ & Short-term (1-2 years) & Long-term (up to 5 years) & & \\
\hline 3 & SPPSC $^{*}$ Organizer & $\begin{array}{l}\text { Afghanistan } \\
\text { Government }\end{array}$ & Local NGOs & $\begin{array}{l}\text { International } \\
\text { NGOs }\end{array}$ & \\
\hline 4 & Location & Injil & Pashtun Zarghun & Ghoriyan & \\
\hline 5 & Machinery & Not Available & Plough only & Drying only & Plough + Drying \\
\hline
\end{tabular}

SPPSC (Saffron Production Promotion Service Center).

The first attribute is insurance, which has two levels (uninsured and insured). Insurance refers to (weather-based) crop insurance covering farmers' crop losses due to adverse weather conditions, such as drought, flood, and storms. The insurance supposedly covers AFN 30 thousand per jerib of land, and the insurance premium is included in the service fee payment. The second attribute is a loan term, which has two levels (short term, i.e., 1-2 years, and long term, i.e., up to 5 years). The loan term refers to the repayment period of a loan of AFN 50,000-100,000, which will be given to the farmers to purchase saffron bulbs, fertilizers, and other equipment. The third attribute is the body of service provider, which has three levels (the Afghan government, local NGOs, and international NGOs). "Organizer" refers to the operator that will implement the saffron production promotion 
policy program. The fourth attribute is the location of the saffron farmer service center, which has three levels (Injil, Pashtun Zarghun, and Ghoriyan). Injil and Pashtun Zarghun are the closest districts to the Herat provincial capital, and Ghoriyan is the furthest at approximately 80 kilometers away from the provincial capital of Herat. The saffron farmer service center will offer its facilities to farmers who join the policy program and inform them of the services available. The fifth attribute is machinery, which has four levels (no machinery, plough, drying, and plough and drying). Machinery indicates that the organization administering the program will provide plows and drying machinery to farmers because farmers in rural areas of the country still use oxen and open-air methods to plow fields and dry saffron. The sixth and final attribute is the annual membership fee paid by registered saffron farmers, which has four levels (AFN 8000, 4000, 2000, and 1000).

Based on the attribute and level settings, 2980 policy alternatives can be potentially constructed; of these alternatives, two are randomly selected and paired to create a choice set, and the choice sets are offered to the respondents along with the status quo of not participating in the program as an outside option. Each respondent is asked to rank these three alternatives in each choice set, which is repeated five times.

The scenario described to the respondents prior to the choice experiment is as follows:

Suppose that we were to propose several hypothetical policies to increase saffron production. First, I will show you three options (A, B, and C) of hypothetical policies, and then, you will rank (1, 2, and 3 ) these three choices in the order of your preference. Regarding choices A and B, each choice is a set of 6 attributes. You will answer the question five times.

The proposed hypothetical policies all share the following assumptions:

Assume that there will be (1) a Saffron Production Promotion Service Center (SPPSC) that will make its facilities available only to those farmers who join the program, and we will ask about your preferences regarding its services. (2) Any money collected is fully and appropriately used to improve saffron production. (3) There will be a loan of AFN 50,000-100,000, and we will ask about your preferences regarding its terms. (4) The government is given priority to implement the program.

\subsection{Descriptive Statistics}

The descriptive characteristics of the saffron farmers who participated in the survey are reported in Table 2.

Table 2. Descriptive characteristics of the saffron farmers.

\begin{tabular}{cccccc}
\hline Variable & Obs. & Mean & Std. Dev. & Min & Max \\
\hline Age & 292 & 41.41 & 12.92 & 18 & 80 \\
Gender & 298 & 0.96 & 0.19 & 0 & 1 \\
Marital status & 296 & 0.93 & 0.26 & 0 & 1 \\
Household size & 296 & 7.89 & 3.97 & 2 & 32 \\
Years of education & 296 & 5.32 & 5.22 & 0 & 17 \\
Years of farming experience & 291 & 4.65 & 2.87 & 1 & 16 \\
Farming lot size (jeribs) & 289 & 2.81 & 2.93 & 0.5 & 20
\end{tabular}

Notes: The number of observations is 298 . Age, gender, and years of education is that of household heads. For gender, 1 indicates male and 0 indicates female. For marital status, 1 indicates married and 0 indicates single. One jerib is equal to 2000 square meters.

In our sample, 39.5 percent of the saffron producers were aged below 35 years. Slightly more than a quarter of the respondents ( 27.5 percent) were aged between 36 and 49 years, and 32 percent were aged 50 or above, with a mean age of 41.41 years. Since our survey is conducted with household heads, most respondents are male. The family size ranges between two and 32 members, with an average size of 7.89 members. Years of education has a large variation with slightly less than 40 percent of the respondents having no formal education. Nearly 26 percent of the household heads completed primary school, nearly 15 percent completed secondary education, and 20 percent were high school 
or college graduates. The household with the largest amount of land under saffron cultivation had 20 jeribs (one jerib is equal to $2000 \mathrm{~m}^{2}$ ), while the respondent with the least amount of land under saffron cultivation had 0.5 jerib. Nearly one-third of the households had a farm size in the range of 3-5 jeribs, and the share of households with a small farm size below 2 jeribs was 62 percent. Only 9 percent had a farm size above 6 jeribs.

Most households acquired their land through inheritance, and the remaining 18 and 11 percent of respondents obtained their land through leases and purchases, respectively. Regarding saffron farming experience, nearly 71 percent of the respondents had $1-5$ years of experience, 25 percent of the respondents had 6-10 years of experience, and only 3 percent of the respondents had more than 10 years of saffron farming experience. As noted above, this distribution reflects the fact that saffron cultivation was popularized after 2001.

\subsection{Empirical Strategy}

One of our research objectives was to estimate the impact of each saffron promotion policy attribute on saffron farmers' policy accepting probabilities. Specifically, we estimated the average marginal component effect (AMCE) of each attribute on internal and external choice probabilities. The internal choice probability indicates the likelihood that one of two hypothetical policies was preferred over the alternative policy. In turn, the external choice probability indicates the likelihood that a hypothetical policy was preferred over the status quo without any policy in place.

Regarding the internal choice probability, the hypothetical policy with the higher ranking was assigned a choice indicator of one, and the choice indicator of the alternative policy was zero, without reference to the ranking of the status-quo option. The external choice probability compares the ranking of hypothetical policies and the status quo. Thus, if both policy A and policy B received a higher ranking than the status quo, both policies have an external choice indicator of 1 .

To estimate the causal effects or the internal and external choice probabilities, we followed the approach proposed by Hainmueller et al. [5]. As the attribute levels were randomly assigned, ordinary least squares (OLS) was simply used to estimate the AMCE of each attribute as a coefficient from a linear regression of the choice indicator based on the set of dummy variables for the attribute levels. The population model is as follows:

$$
y_{i t j}=\beta_{0}+\sum_{l=1}^{L} \sum_{d=2}^{D_{l}} \beta_{l d} \alpha_{i t j l d}+u_{i t j}
$$

where $\alpha_{i t j l d}$ is a dummy variable for the dth level of attribute 1 of policy $j=\{A, B\}$ in task $t$ of respondent $i, \mathrm{~L}$ is the number of attributes, $D_{l}$ is the number of levels of attribute $l, \beta_{l d}$ is the coefficient to be estimated as AMCE, and $u_{i t j}$ denotes the error term. (Clustered-robust standard errors at the respondent level are used in all regressions.)

Then, $y_{i t j}=\{0,1\}$ is the binary choice indicator of policy $j$ in task $t$ of respondent $i$. In the estimation of the internal choice probability, $y_{i t j}=1$ if the preference ranking of policy $j$ is higher than that of its alternative policy. In the estimation of the external choice probability, $y_{i t j}=1$ if the preference ranking of policy $j$ is greater than that of the status quo.

This approach has two main advantages. First, the conditional independence holds due to the purely random selection of the attribute levels in each choice set. The average conditional component effect (ACCE) is the impact of a change in a level of one attribute on the choice probability conditional on the other attributes. Given the conditional independence, ACCE is simply obtained by comparing the proportion of outcome $y_{i t j}$ with different levels of the attribute of interest given the other attributes' levels. Then, this ACCE is integrated over all plausible combinations of the other attributes to yield the AMCE that has the overall effect of changing an attribute on the outcome.

The second advantage is that our estimation of the causal effect is non-parametric, and thus, this method does not rely on any restrictive assumptions, such as assumptions related to the functional 
specification of preference or error distribution. Thus, $\hat{\beta}_{l d}$ consistently estimates the causal effect of a change in an attribute level on the respondents' choice probability.

Finally, we conducted a welfare analysis to compute the potential welfare gain obtained by introducing the new saffron production promotion policy. We performed this analysis by estimating the respondents' willingness to pay (WTP) in accepting the policy. Our study enables us to partially identify the WTP distribution that yields the lower bound of the average WTP for accepting the proposed policy.

\section{Results}

The AMCE of the policy attributes on the internal and external choice probabilities are depicted in Figures 2 and 3, respectively. In the figures, a solid circle represents a point estimate of AMCE, and the horizontal bar represents the cluster-robust 95 percent confidence interval. The six attributes included in the estimation are shown on the left side of the figure, and for each attribute, the baseline is represented by a solid circle on a vertical line without a confidence interval or "wings". The levels used as the baseline supposedly define the "worst-case scenario" and include not insured, shortest term loan, the provider being the government of Afghanistan, saffron production promotion service center (SPPSC) location being at the district farthest from the home district of the farmer, no machinery, and an annual payment of AFN 8000. The government is initially set as the baseline for or the "least-preferred" level of the service provider attribute because Afghan citizens assume that NGOs have higher credibility and transparency than their government $[53,54]$.

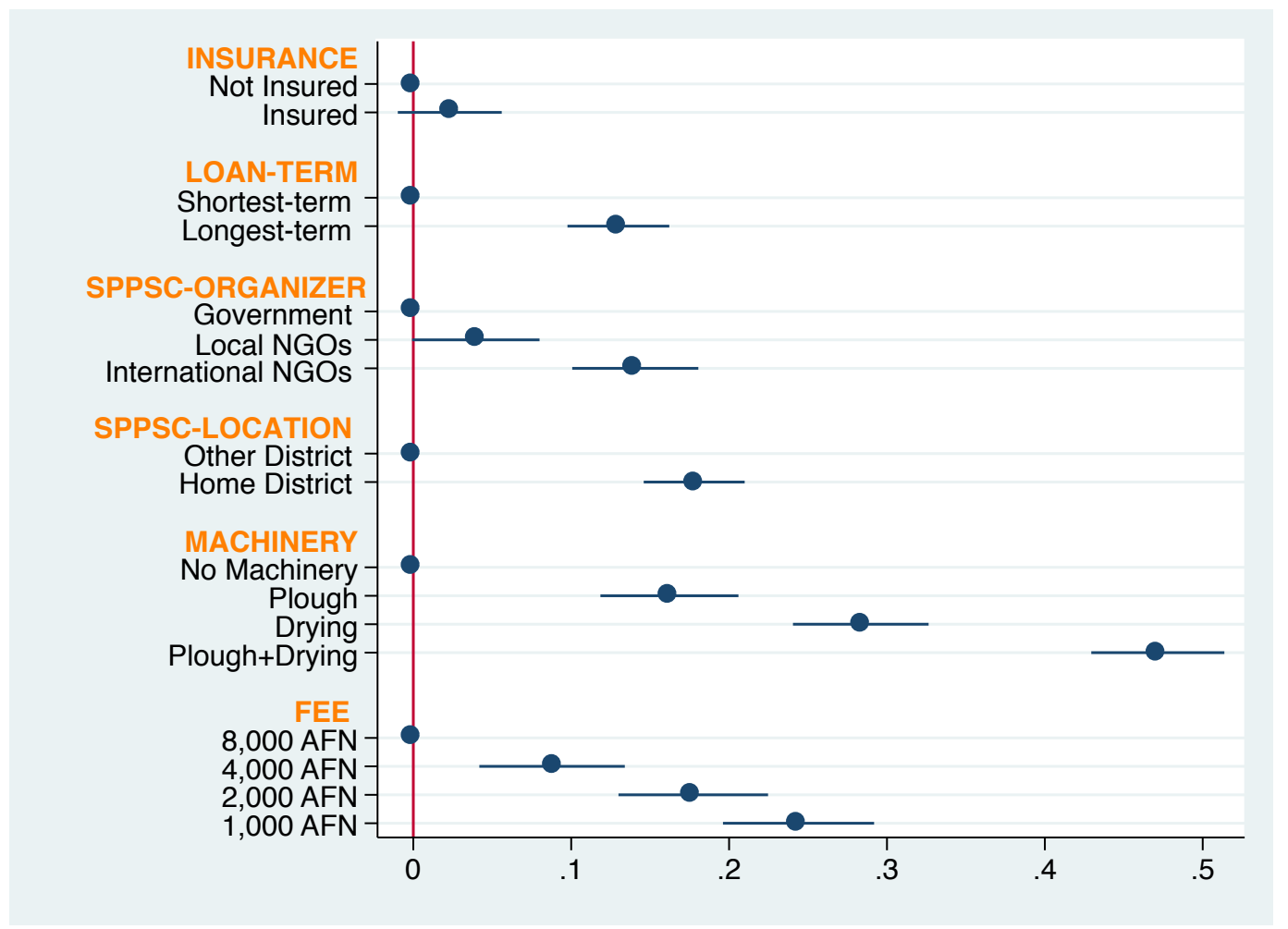

Figure 2. Average marginal component effect (AMCE) of policy attributes on the internal choice probability. Source: Authors' survey. 


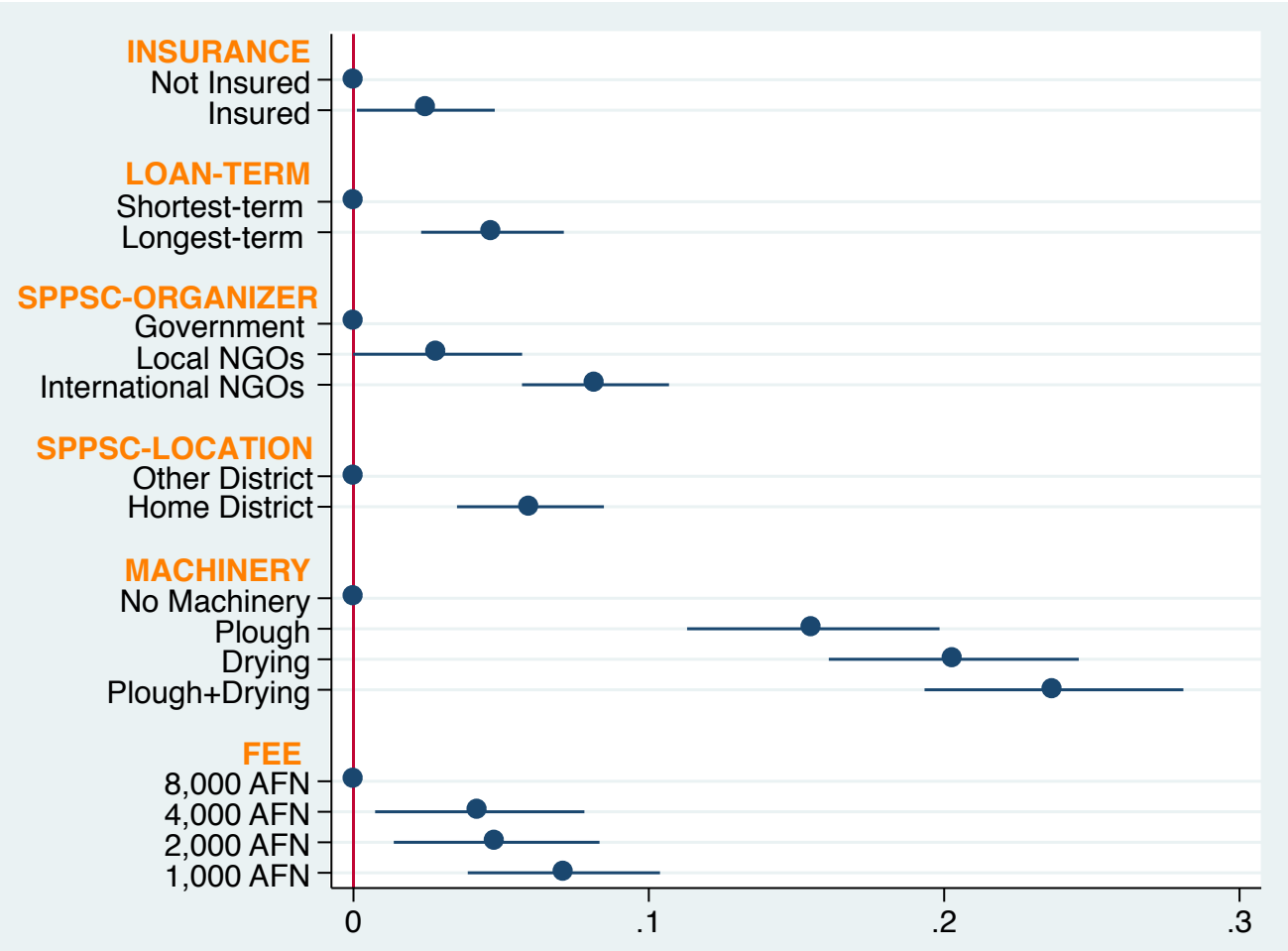

Figure 3. AMCE of policy attributes on the external choice probability. Source: Authors' survey.

\subsection{Internal Choice Probability}

The internal choice probability addresses the likelihood that a policy alternative is preferred over the other alternative policies. The results indicate that the attributes SPPSC organizer, SPPSC location, machinery, and annual fee have a statistically significant and positive AMCE on the internal choice probability. No significant results are observed with the attribute insurance.

Regarding the crop insurance attribute, level two insured has no significant and clear result compared to the baseline of uninsured. Regarding the loan term attribute, level two-a long term of up to 5 years - can increase the internal choice probability by approximately 13 percent relative to the baseline, i.e., short-term loan of 1-2 years. Furthermore, regarding the attribute of an SPPSC organizer, level two local NGOs is significantly estimated (one-sided) to increase a respondent's internal choice probability by approximately 4 percent, while level three international NGOs is estimated to increase a respondent's choice probability by nearly 15 percent compared to the baseline of the government being the operator. Moreover, regarding attribute SPPSC location, the respondents' choice probability is estimated to increase by approximately 18 percent with an SPPSC located in the respondents' home district compared to the baseline of an SPPSC located in another district.

Regarding the machinery attribute, level two-provision of ploughing machine only-increases the respondents' choice probability by 16 percent, while the impact of level three-provision of drying machine only-is nearly 30 percent. Level four-providing both ploughing and drying machines-has the highest impact and increases the respondents' internal choice probability by nearly 50 percent; all figures above are relative to the baseline level of no machinery service provision.

Finally, regarding the annual membership fee attribute, level two, i.e., AFN 4000, can increase the respondents' internal choice probability by approximately 10 percent, level three, i.e., AFN 2000, is estimated to increase slightly less than 20 percent of the respondents' internal choice probability, while the corresponding value of level four, i.e., AFN 1000, is approximately 25 percent; all figures are relative to the baseline of an AFN 8000 annual fee. 


\subsection{External Choice Probability}

The external choice probability is the likelihood that a respondent chooses to accept a policy alternative rather than opting out and choosing the status quo. As shown in Figure 3, the estimation results of the AMCE on the external choice probability follow the same pattern as those of the internal choice probability in general; however, the magnitude of the effect is slightly lower than that of the internal choice probability.

According to the results of the insurance attribute, providing crop insurance shows a statistically insignificant increase in the respondents' choice probability by approximately 2 percent relative to the baseline of uninsured. Regarding the loan term attribute, level two-long term of up to 5 years-increases the respondents' external choice probability by nearly 5 percent relative to the baseline of a short-term loan. This result is consistent with that of the internal choice probability as shown above. These results seem to reflect the fact that saffron farmers face liquidity constraints with limited capacity to invest and save. Saffron requires substantial investment not only due to its high labor requirement and high cost of the saffron bulb but also because it begins to provide a return only in the second year.

Regarding the SPPSC organizer attribute, level two-local NGOs-shows a similar effect as that shown on the internal choice probability, which is currently estimated to increase the respondents' external choice probability by nearly 3 percent. The international NGOs level (level three) has apparent results and is estimated to increase the respondents' policy acceptance probability by 5 percent relative to the baseline, i.e., the sponsor being the government of Afghanistan. Regarding the location of SPPSC attribute, a service center located in the respondents' home district clearly increases the respondents' external choice probability by 6 percent relative to the baseline (SPPSC located in another district). This finding indicates that the location of the SPPSC is important to saffron farmers.

Furthermore, regarding the attribute machinery, the second level plough only, the third level dryer only, and the forth level—both plough and dryer-are estimated to strictly increase the respondents' policy acceptance probability by approximately 16 percent, 20 percent, and 24 percent, respectively, relative to the baseline of no machinery provision. Regarding the annual fee payment attribute, level two AFN 4000, level three AFN 2000, and level four, i.e., AFN 1000, are estimated to increase the probability by approximately 4 percent, 5 percent, and 7 percent, respectively, relative to the baseline annual payment of AFN 8000.

Additionally, the estimated constant term in the external choice probability analysis is as large as 0.58 , indicating that regardless of how the levels of the attributes change, most saffron farmers (58 percent or above) favor the proposed agricultural policy programs. Thus, it seems that saffron farmers are dissatisfied with the current situation without such services in place and call for urgent policy interventions.

\subsection{Welfare Analysis}

In this section, we compute the lower bound of the willingness to pay to engage in the saffron production promotion policy. Here, we show the methodology used for the minimum willingness to pay (WTP) computation and then provide the estimated WTP lower bound, followed by an interpretation of the computed figures and the limitation of our results.

The WTP is a monetary amount that people are willing to pay in exchange for receiving proposed services. The WTP is computed based on the distribution of peoples' WTP between or above given levels of payment. We perform this computation by multiplying the share of peoples' WTP between two neighboring levels of payment by the lower of these levels of payments and then sum all the payment levels.

In our context, the computation of the lower bound of WTP is as follows. We first estimate the marginal choice probabilities by the following regression:

$$
y_{i t j}=\beta_{0}+\beta_{4000} \times D_{i t j 4000}+\beta_{2000} \times D_{i t j 2000}+\beta_{1000} \times D_{i t j 1000}+u_{i t j},
$$


where $y_{i t j}$ is a dummy variable indicating $y_{i t j}=1$ when the preference rank of policy $j$ by individual $i$ in task $t$ is higher than the status quo; $D_{i t j 4000}, D_{i t j 2000}$, and $D_{i t j 1000}$ are dummy variables representing the payment levels $4000 \mathrm{AFN}, 2000 \mathrm{AFN}$, and $1000 \mathrm{AFN}$, respectively, while $8000 \mathrm{AFN}$ remains the baseline; $\beta_{4000}, \beta_{2000}$, and $\beta_{1000}$ are coefficients; and $u_{i t j}$ is the error term. The regression yielded the estimated coefficients $\beta_{4000}=.04, \beta_{2000}=.049, \beta_{1000}=.078$, and $\beta_{0}=.823$, which is constant.

Then, we compute the lower bound of the average WTP as follows:

$$
\mathrm{WTP}_{\text {Lowerbound }}=8000 \times \beta_{0}+4000 \times \beta_{4000}+2000 \times\left[\beta_{2000}-\beta_{4000}\right]+1000 \times\left[\beta_{1000}-\beta_{2000}\right] .
$$

By replacing the values of the estimated coefficients in the equation above, we obtain the following:

$$
W T P_{\text {Lowerbound }}=6799.3(96.52) \text {, }
$$

where the standard error is in parentheses.

The estimated lower bound of the WTP is 6799 AFN (which is equivalent to 87 USD) or as high as $17 \%$ of their per capita income. This finding indicates that the farmers are highly supportive of and enthusiastic to join the policy. Most respondents (more than three quarters) are willing to pay at least AFN 8000 and above.

However, only approximately 8 percent of the respondents' willingness to pay is between AFN 1000 and AFN 8000. Higher levels of the payment attribute could have resulted in an even higher WTP estimate. This augmentation of the payment levels could be explored in future work.

\section{Concluding Remarks}

In developing countries, agriculture is the primary source of employment and income for the majority of the population. In recent years, researchers' interest has been growing to empirically estimate the impact of agricultural development policies in developing countries using conventional conjoint analysis and other parametric approaches, such as a contingent valuation method, to capture the impact of farmer support policies.

This study estimates the preferences of saffron farmers in Herat Province, Afghanistan, particularly their acceptance probability of proposed saffron production promotion policies, based on a randomized conjoint experiment. The results show that inter alia, a saffron production promotion policy including a machinery service provision greatly increases farmers' policy acceptance probability because these farmers are smallholders, are mostly poor, and cannot afford to buy the expensive machinery necessary for saffron production. The significant result indicating that a longer loan term impacts both the internal and external choice probabilities suggests that these farmers also face liquidity constraints; these farmers typically do not have access to formal credit or lending and can only secure loans from family and friends or money lenders with high interest rates. The results strongly suggest that the respondents have an increased probability based on the location of the SPPSC. Thus, the location of the service center is highly important, and farmers strongly prefer to have an SPPSC in their home district. The results also indicate that the respondents believe that international NGOs should implement the programs, likely because the respondents had a favorable past experience with international NGOs who supported and encouraged the farmers to grow saffron by providing productivity enhancing services, such as free saffron bulbs and brief training courses. The external choice probability results indicate that the proposed policy has major support from saffron farmers regardless of its attribute levels. Therefore, the ideal saffron production promotion policy includes packages of provision of necessary machinery services, long-term loans, multiple small but easily accessible saffron promotion service centers instead of one center far from saffron farms, and services rendered by international NGOs; such a policy will gain overwhelming support from saffron farmers in Afghanistan.

Author Contributions: Conceptualization, M.W.A., K.K., and Y.Y.; methodology, K.K. and Y.Y.; software, M.W.A. and G.D.K.; validation, G.D.K., Y.Y. and K.K.; formal analysis, M.W.A. and G.D.K.; investigation, M.W.A. and G.D.K.; resources, Y.Y.; data curation, M.W.A. and G.D.K.; writing—original draft preparation, Y.Y.; writing一review 
and editing, G.D.K.; visualization, G.D.K.; supervision, Y.Y.; project administration, Y.Y.; funding acquisition, Y.Y. All authors have read and agreed to the published version of the manuscript.

Funding: This work was supported by JSPS KAKENHI Grant Number 20K01632.

Acknowledgments: We thank three anonymous referees for constructive suggestions. We also thank Wahdadullah Khpalwak at Nangarhar University, Wahidullah Hussainzada at Balkh University, and Nematullah Hotak at Hiroshima University for providing valuable research support.

Conflicts of Interest: No conflicts of interest declared by authors.

\section{References}

1. National Statistics and Information Authority. Afghanistan Statistical Year- book 2017-2018. Kabul 2019. Available online: https://www.nsia.gov.af:8080/wp-content/uploads/2019/04/Afghanistan-Statistical-Yearbook-2017-18-3.pdf (accessed on 22 April 2020).

2. Akseer, T.; Hayat, K.; Keats, E.C.; Kazimi, S.R.; Maxwell-Jones, C.; Shiwan, M.S.; Swift, D.; Yadgari, M.; Yousufzai, F.A. A Survey of the Afghan People: Afghanistan in 2019. Available online: https://asiafoundation. org/publication/afghanistan-in-2019-a-survey-of-the-afghan-people/ (accessed on 20 April 2020).

3. Kakar, K.; Xuan, T.D.; Haqani, M.I.; Rayee, R.; Wafa, I.K.; Abdiani, S.; Tran, H.D. Current Situation and Sustainable Development of Rice Cultivation and Production in Afghanistan. Agriculture 2019, 9, 49. [CrossRef]

4. Wold Bank. Saffron: A Major Source of Income and an Alternative to Poppy. 2015. Available online: https:// www.worldbank.org/en/news/feature/2015/01/20/saffron-major-source-income-alternative-poppy (accessed on 22 April 2020).

5. Hainmueller, J.; Hopkins, D.J.; Yamamoto, T. Causal Inference in Conjoint Analysis: Un- derstanding Multidimensional Choices via Stated Preference Experiments. Political Anal. 2014, 22, 1-30. [CrossRef]

6. Ministry of Counter Narcotics of the Islamic Republic of Afghanistan. Afghanistan Drug Report 2015. Available online: https://www.unodc.org/documents/afghanistan/UNODC-DRUG-REPORT15-ONLINE270116_1.pdf (accessed on 31 March 2020).

7. Minoia, G.; Pain, A. Saffron: The Social Relations of Production; SLRC Working Paper 48; Secure Livelihoods Research Consortium: London, UK, 2016.

8. DACAAR (Danish Committee for Aid to Afghan Refugees). Saffron: Afghanistan's Red Gold. Available online: http://www.dacaar.org/Publications/5Manual/NRM/SaffronManual.pdf (accessed on 9 July 2019).

9. MAIL (Ministry of Agriculture, Irrigation and Livestock). Afghanistan National Plan for Saffron 2019. Available online: https://www.mail.gov.af/sites/default/files/2019-09/\%D8\%AF\%D8\%B3\%D8\%AA\%20\%D8\% A7\%D9\%88\%D8\%B1\%D8\%AF\%20\%D9\%87\%D8\%A7\%20\%D8\%8C\% (accessed on 15 November 2019).

10. International Taste Institute in Brussels. Awarded Products. 2019. Available online: https://www.tasteinstitute.com/en/awarded-products/awarded-products-list (accessed on 11 February 2020).

11. Melnyk, J.P.; Wang, S.; Marcone, M.F. Chemical and biological properties of the world's most expensive spice: Saffron. Food Res. Int. 2010, 43, 1981-1989. [CrossRef]

12. Ordoudi, S.A.; Cagliani, L.R.; Melidou, D.; Tsimidou, M.Z.; Consonni, R. Uncovering a challenging case of adulterated commercial saffron. Food Control 2017, 81, 147-155. [CrossRef]

13. Khanali, M.; Movahedi, M.; Youse, M.; Jahangiri, S.; Khoshnevisan, B. Investigating energy balance and carbon footprint in saffron cultivation-A case study in Iran. J. Cleaner Prod. 2016, 115, 162-171. [CrossRef]

14. World Bank. Saffron Value Chain Forum for Women in Herat. 2010. Available online: http://documents. worldbank.org/curated/en/510671467993728238/Saffron-value-chain-forum-for-women-in-Herat (accessed on 10 November 2019).

15. Moahid, M.; Maharjan, K.L. Factors Affecting Farmers' Access to Formal and Informal Credit: Evidence from Rural Afghanistan. Sustainability 2020, 12, 1268. [CrossRef]

16. Kumar, A.; Mishra, A.K.; Saroj, S.; Joshi, P.K. Institutional versus non-institutional credit to agricultural households in India: Evidence on impact from a national farmers' survey. Econ. Syst. 2017, 41, 420-432. [CrossRef]

17. APPRO (Afghanistan Public Policy Research Organization). Value Chain Governance and Gender: Saffron Production in Afghanistan. 2010. Available online: https://reliefweb.int/sites/reliefweb.int/files/resources/ 426D739CC76B2E39C12577E4004F47E4-Full_Report.pdf (accessed on 13 February 2020). 
18. Maghsoodi, V. Effect of Different Drying Methods on Saffron (Crocus Sativus L) Quality. Iran. J. Chem. Chem. Eng. 2012, 31, 85-89.

19. Matin, M.A. SAARC Regional Initiative on Agricultural Mechanization. Bangladesh. 2006. Available online: http://un-csam.org/ppta/201411TC10/Papers/SAARC.pdf (accessed on 17 November 2019).

20. Dick, W.; Stoppa, A.; Anderson, J.; Coleman, E.; Rispoli, F. Weather Index-based Insurance in Agricultural Development: A Technical Guide; IFAD: Roma, Italic, 2011; p. 18.

21. Ganaie, D.B.; Singh, Y. Saffron in Jammu \& Kashmir. Int. J. Res. Geogr. 2019, 5, 1-12.

22. Akram-Lodhi, A.H. (Re) imagining agrarian relations? The world development report 2008: Agriculture for development. Dev. Chang. 2008, 39, 1145-1161. [CrossRef]

23. Agbodji, A.E.; Johnson, A.A. Agricultural Credit and Its Impact on the Productivity of Certain Cereals in Togo. Emerg. Markets Fin. Trade. 2019, 1-17. [CrossRef]

24. Nordjo, R.E.; Adjasi, C.K. The impact of credit on productivity of smallholder farmers in Ghana. Agric. Finance Rev. 2019, 80, 91-109. [CrossRef]

25. Florence, N.; Nathan, S. The Effect of Commercial Banks' Agricultural Credit on Agricultural growth in Uganda. Afr. J. Econ. Rev. 2020, 8, 162-175.

26. Yi, Q.; Chen, M.; Sheng, Y.; Huang, J. Mechanization services, farm productivity and institutional innovation in China. China Agric. Econ. Rev. 2019, 11, 536-554.

27. Takeshima, H.; Hatzenbuehler, P.L.; Edeh, H.O. Effects of agricultural mechanization on economies of scope in crop production in Nigeria. Agric. Syst. 2020, 177, 102691. [CrossRef]

28. Sibiko, K.W.; Qaim, M. Weather index insurance, agricultural input use, and crop productivity in Kenya. Food Secur. 2020, 12, 151-167. [CrossRef]

29. Salazar, C.; Jaime, M.; Pinto, C.; Acuña, A. Interaction between crop insurance and technology adoption decisions: The case of wheat farmers in Chile. Aus. J. Agric. Resour. Econ. 2019, 63, 593-619. [CrossRef]

30. Yu, J.; Sumner, D.A. Effects of subsidized crop insurance on crop choices. Agri. Econ. 2018, 49, 533-545. [CrossRef]

31. Fahad, S.; Jing, W. Evaluation of Pakistani farmers' willingness to pay for crop insurance using contingent valuation method: The case of Khyber Pakhtunkhwa province. Land Use Policy 2018, 72, 570-577. [CrossRef]

32. Clarke, D.J.; Mahul, O.; Rao, K.N.; Verma, N. Weather Based Crop Insurance in India; The World Bank: Washington, DC, USA, 2012.

33. Baidu-Forson, J.; Waliyar, F.; Ntare, B.R. Farmer preferences for socioeconomic and technical interventions in groundnut production system in Niger: Conjoint and ordered probit analyses. Agric. Syst. 1997, 54, 463-476. [CrossRef]

34. Das, A.; Senapati, M.; John, J. The impact of Agricultural Credit on Agriculture Production: An Empirical Analysis in India. Reserve Bnk. India Occ. Pap. 2009, 30, 1118-1124.

35. Wang, K.; Zhang, Q.; Kimura, S.; Akter, S. Is the crop insurance program effective in China? Evidence from farmers analysis in five provinces. J. Integ. Agric. 2015, 14, 2109-2120. [CrossRef]

36. Maalouf, A.; Chalak, A. Farmers' willingness to pay for operating a collective postharvest refrigeration unit in an eastern Mediterranean rural community. J. Agric. Food Syst. Community Dev. 2019. [CrossRef]

37. Shee, A.; Azzarri, C.; Haile, B. Farmers' willingness to pay for improved agricultural tech- nologies: Evidence from a field experiment in Tanzania. Sustainability 2020, 12, 216. [CrossRef]

38. Wang, W.; Jin, J.; He, R.; Gong, H.; Tian, Y. Farmers' willingness to pay for health risk reductions of pesticide use in China: A contingent valuation study. Int. J. Environ. Res. Pub. Health 2018, 15, 625. [CrossRef]

39. Ouédraogo, M.; Barry, S.; Zougmoré, R.B.; Partey, S.T.; Somé, L.; Baki, G. Farmers' willing- ness to pay for climate information services: Evidence from cowpea and sesame producers in Northern Burkina Faso. Sustainability 2018, 10, 611. [CrossRef]

40. Dastgir, G.; Kawata, K.; Yoshida, Y. Effect of Forced Relocation on Household Income and Consumption Patterns: Evidence from the Aynak Copper Mine Project in Afghanistan. J. Dev. Stud. 2018, 54, 2061-2077. [CrossRef]

41. CSO (Central Statistics Organization). Afghanistan Living Conditions Survey. 2016-17. Kabul. 2018. Available online: https://washdata.org/sites/default/files/documents/reports/2018-07/Afghanistan\%20ALCS\% 202016-17\%20Analysis\%20report.pdf (accessed on 24 April 2020). 
42. UNODC (United Nations Office on Drugs and Crime). Afghanistan Opium Survey 2018: Cultivation and Production. Available online: https://www.unodc.org/documents/crop-monitoring/Afghanistan/ Afghanistan_opium_survey_2018.pdf (accessed on 26 April 2020).

43. Greenfield, V.A.; Paoli, L.; Reuter, P.H. Is Medicinal Opium Production Afghanistan's Answer?: Lessons From India and the World Market. J. Drug Policy Anal. 2009, 2, 2. [CrossRef]

44. Mansfield, D. On the frontiers of development: Illicit poppy and the transformation of the deserts of southwest Afghanistan. J. Illicit Econ. Dev. 2019, 1, 330-345. [CrossRef]

45. Stewart, M. Afghanistan's Opium Economy. Undergraduate J. Political Sci. 2019, 16, 57.

46. Ministry of Agriculture Irrigation and Livestock. Kabul. Afghanistan. Available online: https://www.mail. gov.af/index.php/en/node/580 (accessed on 28 April 2020).

47. Ministry of Rural Rehabilitation and Development. Kabul. Afghanistan. Available online: http://old.mrrd. gov.af/en/page/69/7353 (accessed on 28 April 2020).

48. Ministry of Rural Rehabilitation and Development. Afghanistan Rural Enterprise Development Program (AREDP). Kabul. Afghanistan. Available online: http://aredpmrrd.gov.af/eng/index.php/about-us (accessed on 28 April 2020).

49. Danish, Z. Promotion of Saffron Cultivation: Progresses and Programs. 2017. Available online: https: //ocs.gov.af/en/article_details/35 (accessed on 27 April 2020).

50. Caiserman, A.; Dumas, D.; Bennafla, K.; Faour, G.; Amiraslani, F. Application of Remotely Sensed Imagery and Socioeconomic Surveys to Map Crop Choices in the Bekaa Valley (Lebanon). Agriculture 2019, 9, 57. [CrossRef]

51. Katawazy, A.S. A Comprehensive Study of Afghan Saffron. Report of Research, Planning and Policy Directorate, Afghanistan Investment Support Agency. Kabul, Afghanistan 2013. Available online: https://www.doc-developpement-durable.org/file/Culture-epices/safran/Commercial/A\% 20comprehensive\%20study\%20of\%20afghan\%20saffron.pdf (accessed on 16 February 2020).

52. World Bank. Afghanistan-Understanding Gender in Agricultural Value Chains: The Cases of Grapes / Raisins, Almonds and Saffron in Afghanistan; World Bank: Washington, DC, USA, 2011; Available online: http://documents.worldbank.org/curated/en/565761468195558713/Afghanistan-Understanding-gender-inagricultural-value-chains-the-cases-of-grapes-raisins-almonds-and-saffron-in-Afghanistan (accessed on 31 March 2020).

53. Jelinek, E. A Study of NGO Relations with Government and Communities in Afghanistan. Agency Coordinating for Afghan Relief 2006. Available online: https://www.alnap.org/system/files/content/resource/ files/main/381c64cc0ebda2b7c1257704004609c5-full-report.pdf (accessed on 31 March 2020).

54. The Asia Foundation. A Survey of the Afghan People: Afghanistan in 2016. Available online: https: //asiafoundation.org/publication/afghanistan-2016-survey-afghan-people/ (accessed on 20 August 2019). 